\title{
Aerobic Utilization of Low Concentrations of Galactose by Lactobacillus plantarum
}

\author{
By H. DIRAR* AND E. B. COLLINS \\ Department of Food Science and Technology, \\ University of California, Davis, California, 95616, U.S.A.
}

(Received I6 April 1973)

\begin{abstract}
SUMMAR Y
$Y_{\text {garactne }}$ was 44 for Lactobacillus plantarum grown aerobically in defined medium containing I to $6 \mu \mathrm{mol}$ galactose $/ \mathrm{ml}$. Nevertheless, $93 \%$ of the galactose was converted to acetate, and the $Y^{\mathrm{ATP}}$ was II.3. Yields were not appreciably less if $0.5 \%$ acetate or $\mathrm{I} \cdot 0 \times 10^{-4} \mathrm{M}$ arsenite was added to the medium, but they were considerably lower if riboflavin was omitted. Lactobacillus plantarum, subsequent to converting low concentrations of hexose to pyruvate by the Embden-MeyerhofParnas pathway, can apparently gain, under aerobic conditions, approximately two additional mol ATP/mol hexose by converting most of the pyruvate to acetate. Lipoic acid and coenzyme A were not involved in the production of acetate; riboflavin was involved in the utilization of oxygen as an electron acceptor.
\end{abstract}

\section{INTRODUCTION}

Molar growth yields and end-products produced from limiting concentrations of glucose or galactose were determined for five species of Lactobacillus, including L. plantarum, by Dirar \& Collins (1972). $Y_{\text {glueose }}$ values for deep cultures of lactobacilli in a defined medium varied from 20 to $33^{\circ} 0$. $Y_{\text {galactose }}$ values for L. plantarum were 25.7 to $33^{\circ} 7$ for deep cultures in the defined medium and 32.5 for an anaerobic culture in a complex medium. The higher yields were obtained with substrate concentrations less than $6 \mu \mathrm{mol} / \mathrm{ml}$. Yet each of the species produced acetate, and $Y^{\text {ATP }}$ values corrected for the energy gained from conversion of pyruvate to acetate were 10.0 to 10.9 , close to 10.5 , proposed as a standard value by Bauchop \& Elsden (1960).

Two mechanisms for converting pyruvate to acetate without formate production have been reported for lactic acid bacteria, each yielding one mol ATP/mol pyruvate. One involves lipoic acid and coenzyme A (CoA) and has been studied extensively with Streptococcus faecalis (O’Kane \& Gunsalus, I948; O'Kane, I950; Gunsalus, Dolin \& Struglia, 1952). Acetyl-CoA is formed as an intermediate and converted to acetate via acetyl-phosphate. In the other mechanism, reported for Lactobacillus delbrueckii (Hager, Geller \& Lipmann, I954), acetyl-phosphate is formed from pyruvate without involving lipoic acid or CoA.

This paper reports on the mechanism used by Lactobacillus plantarum for converting pyruvate to acetate and data on its aerobic utilization of low concentrations of galactose. L. plantarum and galactose were selected for study because this organism is typically homofermentative and does not exhibit the lytic phenomenon when grown on galactose rather than glucose (Dirar \& Collins, 1972).

\footnotetext{
* Present address: Faculty of Agriculture, University of Khartoum, Khartoum, Sudan.
} 


\section{METHODS}

Organism and preparation of inocula. Lactobacillus plantarum ATCC $80 \mathrm{I} 4$ was grown at $30{ }^{\circ} \mathrm{C}$ in the basal medium with galactose added. Bacteria in the exponential phase of growth were harvested by filtering with a Sartorius filter (pore size, $0.45 \mu \mathrm{m}$ ), washed twice with basal medium (without galactose), and suspended in basal medium.

Medium. The basal medium was the defined medium of Henderson \& Snell (I948) as modified by Oxenburgh \& Snowswell (1965), except that we used salts B (MacLeod \& Snell, I947) instead of salts $\mathrm{C}$. The medium was adjusted to $\mathrm{pH} 6 \cdot 8 \pm 0 \cdot \mathrm{I}$ and sterilized by autoclaving. Galactose solutions were sterilized by filtering with a microporous porcelain filter (no. VFA-54-03; Selas Flotronics, Springhouse, Pennsylvania, U.S.A.) and added aseptically.

Cultivation methods. Yields were determined in $100 \mathrm{ml}$ medium in $250 \mathrm{ml}$ Erlenmeyer flasks at $30^{\circ} \mathrm{C}$ in a G 76 gyratory water-bath shaker (New Brunswick Scientific Co., New Brunswick, New Jersey, U.S.A.). The agitation rate was $120 \mathrm{rev} . / \mathrm{min}$. Deep culture conditions were those described by Dirar \& Collins (1972).

Growth and yield measurements. Growth was followed by measuring extinction, E, at $600 \mathrm{~nm}$ with a Beckman spectrophotometer, model DB, with $\mathrm{I} \mathrm{cm}$ cuvettes. Each reported molar growth yield was taken from a curve constructed from data obtained with several limiting concentrations of galactose. Bacterial mass was determined from a standard curve relating $E$ to dry wt. $E$ corresponding to I $\mathrm{mg}$ dry wt $/ \mathrm{ml}$ was 4.00 . Bacteria, grown in the basal medium containing Io to $\mathrm{I} 2 \mu \mathrm{mol}$ galactose $/ \mathrm{ml}$, were harvested at maximal $E$ by centrifugation at $800 \mathrm{~g}$ at $4{ }^{\circ} \mathrm{C}$ and washed three times in volumes of de-ionized distilled water equal to that of the original medium. Different amounts of washed bacteria were suspended in distilled water, determinations of $E$ were made (with distilled water as the internal standard), $50 \mathrm{ml}$ of each dilution was placed in a pre-weighed aluminium dish and dried to constant weight at $105{ }^{\circ} \mathrm{C}$, and $E$ values were plotted against dry weights. Dry weights were also determined gravimetrically in some experiments and found not to differ from those determined by the usual procedure.

Analytical methods. Lactic acid was determined by the colorimetric method of Barker \& Summerson (194I). Ethanol was determined by alcohol Stat Pack (Worthington Biochemical Corporation, Freehold, New Jersey, U.S.A.). Total volatile acids were determined by the procedure of Neish (I950), formate by the method of Wood \& Gest (I957), and acetate by subtracting formate from total volatile acids. Distillations and titrations were performed with continuous nitrogen sparging.

\section{RESULTS}

\section{Aerobic yields and end-products}

Lactobacillus plantarum did not grow in the defined medium in absence of galactose. With I to $6 \mu \mathrm{mol}$ galactose $/ \mathrm{ml}$, the $Y_{\text {galactose }}$ value (Table I) was about $50 \%$ higher than those reported by Dirar \& Collins (1972) for a deep culture in the defined medium (30.0) and an anaerobic culture in complex medium (32.5). Carbon recovery, calculated from end-products and assuming production of $\mathrm{CO}_{2}$ equalled production of acetate, was good (IOI \%). Though $93 \%$ of the galactose was converted to acetate, the resulting $Y^{\text {ATP }}$ value was I I 3 , only slightly above the values found by Dirar \& Collins (1972). Addition of catalase to decompose any hydrogen peroxide that might be produced had little effect on the results, and it was apparent that the production of hydrogen peroxide by L. plantarum while growing on the low concentrations of galactose was negligible or absent, substantiating the results 
Table I. Molar growth yields and end-products produced aerobically from low concentrations* of galactose by Lactobacillus plantarum

\begin{tabular}{|c|c|c|c|c|c|c|}
\hline \multirow[b]{2}{*}{$\begin{array}{l}\text { Medium } \\
\text { modification }\end{array}$} & \multicolumn{3}{|c|}{ End-products $\dagger / \mathrm{mol}$ galactose } & \multirow{2}{*}{$\begin{array}{c}Y_{\text {galactose }} \\
\text { (g dry wt/ } \\
\text { mol) }\end{array}$} & \multirow{2}{*}{$\begin{array}{c}\mathrm{ATP} / \mathrm{mol} \\
\text { galactose } \\
(\mathrm{mol})\end{array}$} & \multirow{2}{*}{$\begin{array}{c}Y^{\text {ATP }} \\
(\mathrm{g} \text { dry wt } \\
\text { mol) }\end{array}$} \\
\hline & $\begin{array}{l}\text { Lactate } \\
(\mathrm{mol})\end{array}$ & $\begin{array}{l}\text { Acetate } \\
(\mathrm{mol})\end{array}$ & $\begin{array}{l}\text { Total } \\
(\mathrm{mol})\end{array}$ & & & \\
\hline None & $0 \cdot 14$ & $1 \cdot 88$ & $2 \cdot 02$ & $44 \cdot 0$ & $3 \cdot 90$ & I I 3 \\
\hline Catalase added & 0.09 & $1 \cdot 92$ & $2 \cdot 01$ & $45^{\circ} 0$ & $3 \cdot 93$ & I I 4 \\
\hline Acetate added $(0.5 \%)$ & 0.13 & - & - & $43 \cdot 6$ & - & 一 \\
\hline $\begin{array}{l}\text { Arsenite added } \\
\left(\mathrm{I} \cdot \mathrm{O} \times 1 \mathrm{IO}^{-4} \mathrm{M}\right)\end{array}$ & $0 \cdot 20$ & $I \cdot 76$ & $1 \cdot 96$ & $41 \cdot 3$ & $3 \cdot 72$ & $I I \cdot I$ \\
\hline Riboflavin omitted & 0.90 & $I \cdot 22$ & $2 \cdot 12$ & $34 \cdot 3$ & $3 \cdot 34$ & $10 \cdot 3$ \\
\hline
\end{tabular}

of Fukui (196I) and Mizushima \& Kitahara (1964). Neither formate nor ethanol was found in these cultures or in any of those reported on below.

\section{Yields not influenced by added acetate}

Were CoA required by Lactobacillus plantarum in the conversion of pyruvate to acetate, addition of acetate to the cultures should have decreased the availability of CoA by resulting in the formation of acyl esters (Hespell, Joseph \& Mortlock, I 969) and decreased or prevented the production of acetate, as found for Streptococcus faecalis by Johnson \& Collins (I973). Addition of $0.5 \%(\mathrm{w} / \mathrm{v})$ acetate to cultures of $L$. plantarum, however, did not increase lactate production or decrease bacterial yield (Table I), and it was apparent that the production of acetate by the organism had not been decreased.

\section{Yields not influenced by added arsenite}

The influence of arsenite, a specific inhibitor of lipoic acid (Losada \& Arnon, 1963), on molar growth yields was tested. Sodium arsenite $\left(\mathrm{IO}^{-3} \mathrm{M}\right)$ prevented growth of Lactobacillus plantarum, but $\mathrm{IO}^{-4} \mathrm{M}$, the concentration found by Hager et al. (I954) to give $95 \%$ inhibition of pyruvate oxidation by Streptococcus faecalis, decreased the molar growth yield only slightly (Table I), indicating that lipoic acid was not involved in the production of acetate. Results determined under deep culture conditions were similar except that more lactate and less acetate were produced. Approximately equal amounts of acetate and lactate were produced and $Y_{\text {galactose }}$ values were the same with or without $10^{-4} \mathrm{M}$-arsenite added to the medium.

\section{Yields influenced by omission of riboflavin}

Omission of riboflavin ( $\mathrm{I} \mu \mathrm{g} / \mathrm{ml}$ ), which enhances the dismutation of pyruvate to lactate and acetyl-phosphate by Lactobacillus delbrueckii (Hager et al. 1954), had no effect under deep culture conditions on yield of Lactobacillus plantarum or on the amounts of acetate and lactate produced. The amounts of acetate and lactate were approximately equal, indicative of dismutation (Hager et al. 1954). However, under aerobic conditions, omission of riboflavin from the defined medium influenced yield and end-products (Table I). Less acetate and more lactate were produced, and $Y_{\text {galactose }}$ was only slightly greater than 32.5 , the $Y_{\text {galactose }}$ value found for the organism growing anaerobically (Dirar \& Collins, 1972). 


\section{DISCUSSION}

Lactic acid bacteria theoretically should be able to gain $4 \mathrm{~mol}$ ATP/mol hexose fermented, using the Embden-Meyerhof-Parnas (EMP) pathway and converting the pyruvate produced to acetate rather than lactate, except that they require some pyruvate for the synthesis of acetyl-CoA and normally incorporate about $3 \%$ of the growth-limiting hexose fermented into cellular materials (Bauchop \& Elsden, I960; Harvey \& Collins, I963; Dirar \& Collins, 1972). Lactobacillus plantarum, when grown under partial anaerobic conditions (as deep cultures) in a defined medium containing 6 to $17 \mu \mathrm{mol}$ or I to $6 \mu \mathrm{mol}$ galactose $/ \mathrm{ml}$, converted 82 or $58 \%$, respectively, of the galactose to lactate and gained $2.5 \mathrm{r}$ or $2.98 \mathrm{~mol} \mathrm{ATP} / \mathrm{mol}$ galactose (Dirar \& Collins, I 972). Greater lactate production at the higher range of galactose concentrations probably resulted from a higher intracellular concentration of fructose- $1,6-$ diphosphate, reported by Wolin (I964), Anders, Jonas \& Jago (1970), deVries, Kapteijn, van der Beek \& Stouthamer (1970), and Brown \& Whittenberger (1972) to stimulate the activity of lactate dehydrogenases. However, when the organism was grown under aerobic conditions in the defined medium containing only I to $6 \mu \mathrm{mol}$ galactose $/ \mathrm{ml}$, it converted $93 \%$ of the galactose to acetate (only $7 \%$ to lactate) and gained $3.9 \mathrm{~mol} \mathrm{ATP} / \mathrm{mol}$ hexose.

Lactobacillus plantarum apparently did not involve lipoic acid in the production of acetate, and acetate was produced by a mechanism similar to that reported for L. delbrueckii (Hager et al. 1954). Nevertheless, L. plantarum and four other species of Lactobacillus (Dirar \& Collins, 1972) grew on glucose or galactose in the defined medium which contained no lipoic acid or acetate. (Growth of Streptococcus diacetilactis or S. cremoris in the medium requires addition of acetate or lipoic acid.) How L. plantarum synthesizes sufficient acetyl-CoA for the initiation of growth in the absence of added lipoic acid or acetate is not known. We suspect that this organism, similar to S. faecalis (Johnson \& Collins, 1973), synthesizes sufficient lipoic acid for the initiation of growth, particularly since $10^{-3} \mathrm{M}$-arsenite prevented its growth. Another possibility is that the organism first produces some acetate and then synthesizes acetyl-CoA from the acetate by means of acetate kinase and phosphotransacetylase (Jones, Black, Flynn \& Lipmann, 1953).

Lactobacillus plantarum, when grown on low concentrations of galactose (I to $6 \mu \mathrm{mol} / \mathrm{ml}$ ) under anaerobic or aerobic conditions, converts galactose to pyruvate by the EMP pathway and thereby gains two mol ATP/mol hexose fermented. Subsequently, the organism gains additional ATP by forming acetate from part of the pyruvate if the conditions are anaerobic (Dirar \& Collins, 1972), or approximately two additional mol ATP/mol hexose by converting most of the pyruvate to acetate if the conditions are aerobic and riboflavin is present. Riboflavin apparently was involved in the transfer of electrons to oxygen, and use of oxygen rather than pyruvate as terminal hydrogen acceptor explains our finding this homofermentative species of Lactobacillus to produce acetate from $93 \%$ of the pyruvate produced from the low concentrations of galactose.

\section{REFERENCES}

Anders, R. F., Jonas, H. A. \& JAGO, G. R. (1970). A survey of the lactate dehydrogenase activities in group $\mathrm{N}$ streptococci. Australian Journal of Dairy Technology 25, 73-76.

BARKer, S. B. \& Summerson, W. H. (I94I). The colorimetric determination of lactic acid in biologic material. Journal of Biological Chemistry $\mathbf{1 3 8}, 535-554$.

BAuCHOP, T. \& ElSDEN, S. R. (I960). The growth of micro-organisms in relation to their energy supply. Journal of General Microbiology 23, 457-469. 
Brown, A. T. \& Whittenberger, C. L. (1972). Fructose-1,6-diphosphate-dependent lactate dehydrogenase from a cariogenic streptococcus: purification and regulatory properties. Journal of Bacteriology r1o, $604-6 \mathrm{I} 5$.

Dirar, H. \& Collins, E. B. (1972). End-products, fermentation balances, and molar growth yields of homofermentative lactobacilli. Journal of General Microbiology 73, 233-238.

FukUI, S. (I961). Crystalline DPNH oxidase from Lactobacillus plantarum no. I I. Agricultural and Biological Chemistry 25, 876-878.

Gunsalus, I.C., Dolin, M. I. \& Struglia, L. (1952). Pyruvic acid metabolism. III. A manometric assay for pyruvate oxidation factor. Journal of Biological Chemistry I94, 849-857.

HaGer, L. P., Geller, D. M. \& LipmanN, F. (1954). Flavoprotein catalyzed pyruvate oxidation in Lactobacillus delbrueckii. Federation Proceedings $\mathbf{1 3}, 734-738$.

Harvey, R. J. \& Collins, E. B. (1963). Roles of citrate and acetoin in the metabolism of Streptococcus diacetilactis. Journal of Bacteriology 86, $130 \mathrm{I}-\mathrm{I} 307$.

Henderson, L. M. \& SNell, E. E. (I948). A uniform medium for determination of amino acids with various microorganisms. Journal of Biological Chemistry 172, I 5-29.

Hespell, R. B.. Joseph, R. \& Mortlock, R. P. (1969). Requirement for coenzyme A in the phosphoclastic reaction of anaerobic bacteria. Journal of Bacteriology 1oo, I328-1 334.

Johnson, M. G. \& Collins, E. B. (1973). Synthesis of lipoic acid by Streptococcus faecalis $10 \mathrm{C}$ I and endproducts produced anaerobically from low concentrations of glucose. Journal of General Microbiology 78, 47-55.

Jones, M. E., Black, S., Flynn, R. \& Lipmann, F. (1953). Acetyl coenzyme A synthesis through pyrophosphoryl split of adenosine triphosphate. Biochemica et biophysica acta 12, 14 I-I 49 .

LosAda, M. \& ARnON, D. I. (1963). Selective inhibitors of photosynthesis. In Metabolic Inhibitors, vol. 2, pp. 559-593. Edited by R. M. Hochster and J. H. Quastel. New York: Academic Press.

MacLeod, R. A. \& SNell, E. E. (1947). Some mineral requirements of the lactic acid bacteria. Journal of Biological Chemistry $\mathbf{1 7 0}, 35 \mathrm{I}-365$.

Mizushima, S. \& Kitahara, K. (1964). Quantitative studies on glycolytic enzymes in Lactobacillus plantarum. 5. Enzymatic basis of oxygen independency of lactic fermentation. Agricultural and Biological Chemistry 28, 344-347.

NeISH, A. C. (1950). In Analytical Methods for Bacterial Fermentations, pp. I6-I 7. Report no. 46-8-3, National Research Council of Canada.

O'KANE, D. J. (1950). Influence of the pyruvate oxidation factor on the oxidative metabolism of glucose by Streptococcus faecalis. Journal of Bacteriology 6o, 449-458.

O'Kane, D. J. \& Gunsalus, 1. C. (1948). Pyruvic acid metabolism. A factor required for oxidation by Streptococcus faecalis. Journal of Bacteriology 56, 499-506.

Oxenburgh, M. S. \& SNowswell, A. M. (1965). Use of molar growth yields for the evaluation of energyproducing pathways in Lactobacillus plantarum. Journal of Bacteriology 89, 9r3-9I4.

deVries, W., Kapteijn, W. M. C., van der Beek, E. G. \& Stouthamer, A. H. (1970). Molar growth yields and fermentation balances of Lactobacillus casei $\mathrm{L}_{3}$ in batch cultures and in continuous cultures. Journal of General Microbiology 63, 333-345.

Wolin, M. J. (1964). Fructose-I,6-diphosphate requirement of streptococcal lactic dehydrogenases. Science, New York 146, 775-777.

Wood, H. G. \& GeST, H. (I957). Determination of formate. In Methods in Enzymology, vol. 3, p. 385. Edited by S. P. Colowick and N. O. Kaplan. New York: Academic Press. 